\title{
A novel p70 S6 kinase-microRNA biogenesis axis mediates multicellular spheroid formation in ovarian cancer progression
}

\author{
Sophia So Ngo Lam¹, Carman Ka Man Ip ${ }^{1}$, Abby Sin Chi Mak ${ }^{1}$, Alice Sze Tsai Wong ${ }^{1}$ \\ ${ }^{1}$ School of Biological Sciences, University of Hong Kong, Hong Kong \\ Correspondence to: Alice Sze Tsai Wong, e-mail: awongl@hku.hk \\ Keywords: p70 S6 kinase, microRNA biogenesis, multicellular spheroid formation, ovarian cancer \\ Received: January 06, $2016 \quad$ Accepted: April 26, $2016 \quad$ Published: May 13, 2016
}

\section{ABSTRACT}

Ovarian cancer is the leading cause of death of all gynecologic tumors, associated with widespread peritoneal dissemination and malignant ascites. Key to this is the ability to form multicellular spheroids (MCS); however, the tumor-specific factors that regulate MCS formation are unclear. p70 S6 kinase $\left(p 70^{56 K}\right)$, which is a downstream effector of phosphatidylinositol 3-kinase/Akt, is frequently constitutively active in ovarian carcinoma. Here we identify $\mathrm{p}^{70^{\mathrm{s}} \mathrm{K}}$ as a vital regulator of MCS formation. We also uncover a new mechanism of $\mathrm{p} 70^{\mathrm{s}} \mathrm{K}$ function as a component of the microRNA biogenesis machinery in this process. We show that $\mathrm{p} 70^{\mathrm{s} 6 \mathrm{~K}}$ phosphorylates, and inhibits the interaction of tristetraprolin (TTP) and Dicer that promotes the expression of a subset of miRNAs, including the maturation of miR-145. Twist and Sox9 are two divergent targets of miR-145, thereby enhancing $\mathrm{N}$-cadherin, but not other cadherin, expression and MCS formation. Activating miR-145 suppresses ovarian tumor growth and metastasis in an orthotopic xenograft mouse model. Meta-analysis

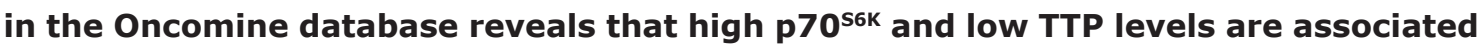
with ovarian tumor progression. These results define a critical link between $\mathrm{p} 70^{\mathrm{s} 6 \mathrm{~K}}$, miRNA maturation, and MCS formation that may underlie poor clinical outcome of ovarian cancer patients for developing novel therapeutic strategies.

\section{INTRODUCTION}

Ovarian cancer is the leading cause of death from gynecologic cancers [1]. The majority of cases $(70 \%)$ are diagnosed after the disease has already metastasized with widespread peritoneal dissemination and malignant ascites. Several lines of evidence suggest that multicellular spheroids (MCS) play an important role in the biology of ovarian cancer. First, ovarian cancer cells in peritoneal ascites exist as MCS (30-200 $\mu \mathrm{m})$ [2]. Second, MCS can readily attach to and disaggregate on the peritoneum $[3,4]$. Third, MCS recapitulate aggressive tumorigenesis when transplanted into mice [5]. Fourth, ovarian cancer cells routinely propagating in vitro as MCS may generate a subpopulation of cancer stem/ tumor-initiating cells, which are highly neoplastic [6-8]. These MCS are also particular critical in addressing the challenge of treating ovarian cancer in which current therapies are ineffective (5-year survival $<25 \%$ ). However, the factors that regulate MCS formation are largely unknown.
There is growing evidence supports the importance of p70 S6 kinase $\left(\mathrm{p} 70^{\mathrm{S} 6 \mathrm{~K}}\right)$, a downstream effector of $\mathrm{PI} 3 \mathrm{~K} / \mathrm{Akt}$, in ovarian cancer [9]. p70 ${ }^{\mathrm{S} 6 \mathrm{~K}}$ activation occurs significantly more often in ovarian tumors than in benign or borderline lesions, and that constitutive activation of $\mathrm{p} 70^{\mathrm{S} 6 \mathrm{~K}}$ correlates with aggressive malignant phenotypes [10]. Although it was originally described as being predominantly involved in cell growth, we have provided the first evidence for a role of $\mathrm{p} 70^{\mathrm{s} 6 \mathrm{~K}}$ in other aspects of tumor progression, such as metastasis [10-12]. However, it is still not known whether $\mathrm{p} 70^{\mathrm{S} 6 \mathrm{~K}}$ affects MCS formation, although this is a key mechanism of ovarian cancer metastasis. The ribosomal protein S6 was the first and most well-known substrate of $\mathrm{p} 70^{\mathrm{S} 6 \mathrm{~K}}$. However, despite the diverse process controlled by $\mathrm{p} 70^{\mathrm{S} 6 \mathrm{~K}}$, only few substrates are known.

MicroRNAs (miRNAs) are small non-coding RNAs that have recently emerged as fundamental posttranscriptional regulators of target gene expression. Although first identified in c. elegans, miRNAs are now known to be expressed in most organisms and aberrant miRNA expression has been implicated in the 
pathogenicity of human cancers [13]. Of equal importance as transcriptional regulation, the processing of premature miRNAs is a critical rate-limiting step in miRNA biogenesis that controls mature miRNA turnover. Primary (pri-) miRNAs are processed into precursor (pre-) miRNAs by the dsRNA-specific ribonulease Drosha, whereas premiRNAs are cleaved to produce mature miRNAs by Dicer $[14,15]$. While detailed insight has been gained into their target genes, little is known about signaling mechanisms controlling miRNA biogenesis, particularly those that relate to disease.

Here we show for the first time that $\mathrm{p} 70^{\mathrm{S} 6 \mathrm{~K}}$ is a pivotal regulator of MCS formation. We also provide mechanistic insight that a unique aspect of the function of $\mathrm{p} 70^{\mathrm{S} 6 \mathrm{~K}}$ by which it suppresses the maturation of miR145 , which controls the turnover of two critical transcripts Twist and Sox 9 in the regulation of $\mathrm{N}$-cadherin through tristetraprolin (TTP)/Dicer-dependent pathway.
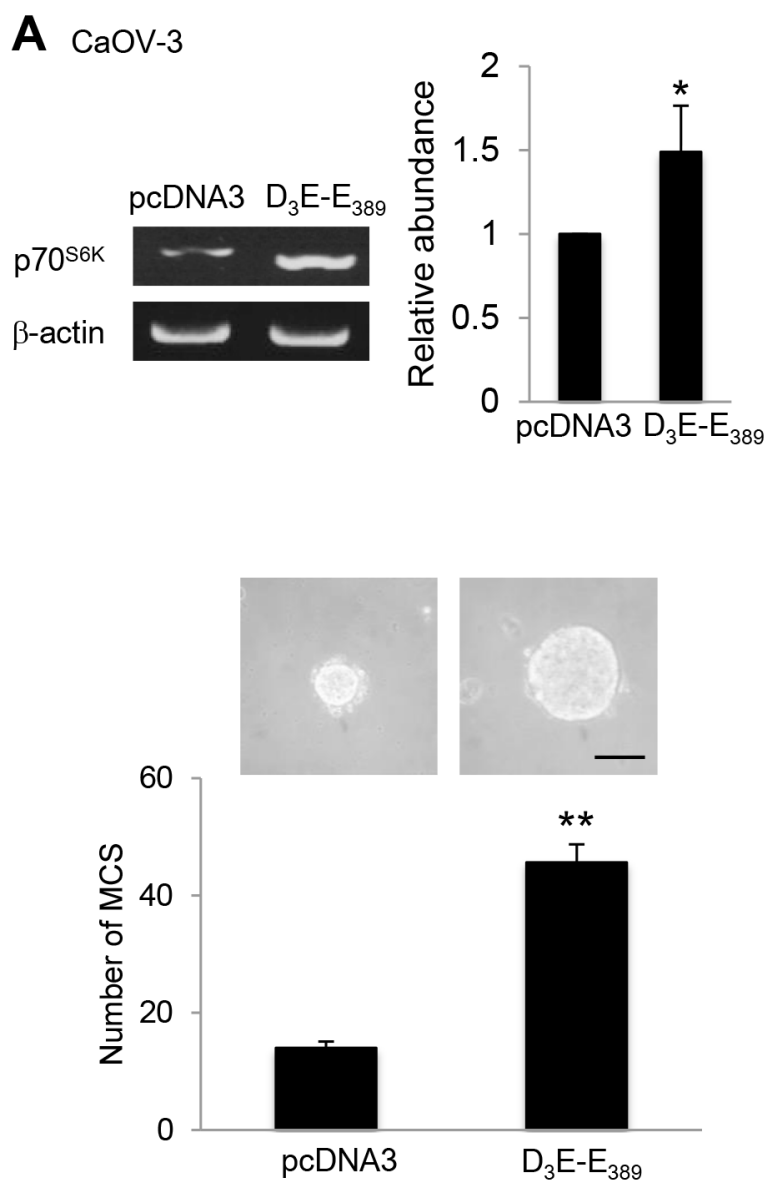

\section{RESULTS}

\section{$\mathrm{p}^{70^{\mathrm{S} 6 \mathrm{~K}}}$ promotes MCS formation}

In addressing the factors that promote MCS formation, we considered the role of $\mathrm{p} 70^{\mathrm{s} 6 \mathrm{~K}}$, which is a key intracellular signaling mediator for the effects of multiple growth factors in the malignant ascites and is frequently hyperactive in human ovarian cancer [12]. Indeed, overexpression of the constitutively active $\mathrm{p} 70^{\mathrm{S} 6 \mathrm{~K}},\left(\mathrm{D}_{3} \mathrm{E}-\mathrm{E}_{389}\right)$ was sufficient to robustly increase MCS formation (3.3-fold) (Figure 1A). Using a siRNAbased silencing approach, p70 ${ }^{\mathrm{S} 6 \mathrm{~K}}$ siRNA significantly suppressed MCS formation, establishing that $\mathrm{p} 70^{\mathrm{S} 6 \mathrm{~K}}$ as an endogenous promoter of MCS formation in ovarian cancer (Figure 1B). A second p70 ${ }^{\mathrm{S} 6 \mathrm{~K}}$ siRNA showed similar results (data not shown), and the nonspecific siRNA had no effect (Figure 1B).
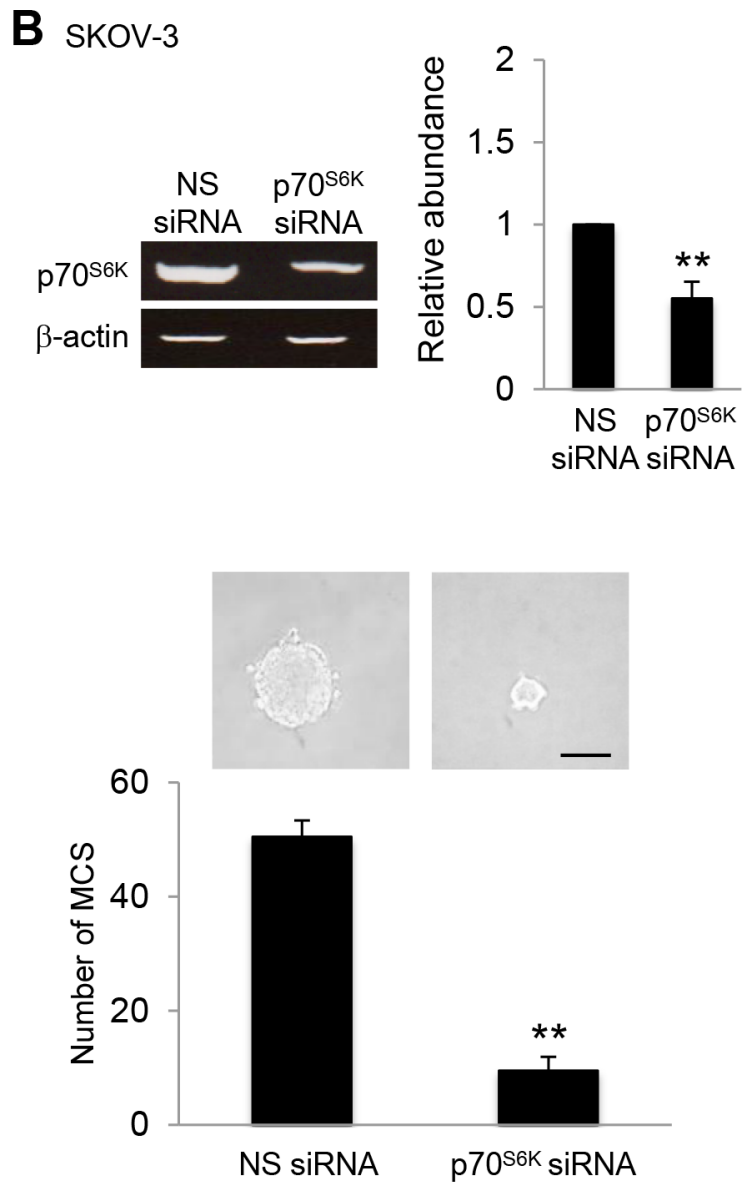

Figure 1: $\mathbf{p 7 0}{ }^{\mathrm{S} 6 \mathrm{~K}}$ promotes MCS formation. A. CaOV-3 cells were transfected with pcDNA3 or constitutively active $\mathrm{p} 70^{\mathrm{S} 6 \mathrm{~K}}$ construct $\left(\mathrm{D}_{3} \mathrm{E}_{-} \mathrm{E}_{389}\right)$ or B. SKOV-3 cells were transfected with nonspecific (NS) siRNA or p70 ${ }^{\mathrm{S} 6 \mathrm{~K}}$ siRNA for 72 hr. Total RNA was extracted and reverse transcription-PCR was performed using $\mathrm{p} 70^{\mathrm{S} 6 \mathrm{~K}}$ sequence-specific primers. $\beta$-actin was included as a control. The band intensities were quantified by densitometric analysis and expression levels relative to that of $\beta$-actin were shown. The number of tumor spheres generated in CaOV-3 and SKOV-3 were photographed and counted. Bar $=100 \mu \mathrm{m}$. Results are presented as the mean \pm SD and were analyzed using paired student's $t$ test. ${ }^{*} P<0.05 ;{ }^{*} P<0.005$, compared with pcDNA3 or NS siRNA. 


\section{$\mathrm{N}$-cadherin is the regulator of MCS phenotype upon $\mathrm{p}^{70^{\mathrm{S} 6 \mathrm{~K}}}$ activation}

Cadherins are major mediators of cell-cell adhesion [16]. To begin addressing whether cadherin has a role in MCS formation, the expression of E-, N-, and P-cadherin, which have key roles in ovarian tumor progression [17] in relation to their ability to form MCS was first examined. Western blot analysis demonstrated that $\mathrm{N}$-cadherin was highly expressed in SKOV-3 and HEYA8 cells, both of which have been shown to most effectively form compact spheroids (Supplementary Figure S1A \& S1B). CaOV-3 and A2780 cells, which possess little or no N-cadherin, showed no MCS formation (Supplementary Figure S1A \& $\mathrm{S} 1 \mathrm{~B})$. Importantly, $\mathrm{p} 70^{\mathrm{s} 6 \mathrm{~K}}$ was expressed at higher levels in SKOV-3 and HEYA8 cells, which exhibit physiologically higher endogenous levels of $\mathrm{N}$-cadherin (Supplementary Figure S1A \& S1B). It is worth noting that this seems to be independent of the endogenous expression of $\mathrm{E}$ - or P-cadherin (Supplementary Figure S1A \& S1B). Of note, depletion of N-cadherin by the use of siRNA, in which reduced the levels of N-cadherin, but not the levels of E- or P-cadherin, inhibited the ability of SKOV-3 and HEYA8 cells to form MCS (Figure 2A). No inhibition was observed for nonspecific siRNA, confirming that the effect is N-cadherin specific (Figure 2A). Similarly, hindering $\mathrm{N}$-cadherin engagement with a functionblocking antibody also ablated MCS formation, whereas control IgG was without effect (Figure 2B). These results suggest that $\mathrm{N}$-cadherin may have a dominant effect over other cadherins on MCS formation of ovarian cancer cells.

\section{$\mathrm{p}^{70}{ }^{\mathrm{S} 6 \mathrm{~K}}$ increases $\mathrm{N}$-cadherin expression via Twist and Sox 9}

To determine whether $\mathrm{p} 70^{\mathrm{S} 6 \mathrm{~K}}$ mediates $\mathrm{MCS}$ formation via $\mathrm{N}$-cadherin, we first overexpressed constitutively active $\mathrm{p} 70^{\mathrm{S} 6 \mathrm{~K}}, \mathrm{D}_{3} \mathrm{E}-\mathrm{E}_{389}$. This resulted in an effective upregulation of N-cadherin (Figure 2C). Conversely, knocking down $\mathrm{p} 70^{\mathrm{s} 6 \mathrm{~K}}$ clearly abolished the induction of N-cadherin (Figure 2D). Furthermore, inhibition of N-cadherin significantly suppressed MCS formation by $\mathrm{D}_{3} \mathrm{E}_{-} \mathrm{E}_{389}$ overexpression (Figure 2E), indicating also a functional correlation between $\mathrm{p} 70^{\mathrm{S} 6 \mathrm{~K}}$ and $\mathrm{N}$-cadherin in MCS formation.

$\mathrm{N}$-cadherin is known to be activated through at least two transcriptional regulators, including Twist and Sox9 [18]. This is also relevant to the clinical situation that Twist and Sox9 are often elevated in malignant ovarian tumors and confer a poor outcome to the late stage ovarian cancer patient survival [19,20]. Given the robust effects of $\mathrm{p} 70^{\mathrm{S} 6 \mathrm{~K}}$ on $\mathrm{N}$-cadherin, we investigated whether $\mathrm{p} 70^{\mathrm{S} 6 \mathrm{~K}}$ regulates expression of these two genes (Twist and Sox9). As shown in Figure 3A, $\mathrm{D}_{3} \mathrm{E} \mathrm{E}_{389}$ markedly induced an increase in Twist and Sox9 mRNA, which correlated with the upregulation of its target gene,
$\mathrm{N}$-cadherin (Figure 3A). In contrast, depletion of Twist and Sox9 through specific siRNAs led to repression of the $\mathrm{D}_{3} \mathrm{E}-\mathrm{E}_{389}$-induced $\mathrm{N}$-cadherin mRNA expression (Figure 3A). Furthermore, siRNA depletion of Twist and Sox9 inhibited MCS formation (Figure 3B), suggesting functional roles for them.

\section{$\mathrm{p}^{70^{\mathrm{S}}}{ }^{\mathrm{K}}$ activation stabilizes Twist and Sox9 mRNAs}

Since the increase of mRNA could result from either increased transcription or mRNA stability, this prompted us to investigate the cellular mechanisms underlying $\mathrm{p} 70^{\mathrm{S}} \mathrm{K} \mathrm{K}$ regulation of Twist and Sox9 mRNAs. Interestingly, $\mathrm{D}_{3} \mathrm{E}_{-} \mathrm{E}_{389}$ was without effect on the induction of luciferase activity driven by Twist- and Sox9-promoter regions (Supplementary Figure S2). We next performed RNA decay analyses using actinomycin D. Twist mRNA $\mathrm{t}_{1 / 2}$ was prolonged in $\mathrm{D}_{3} \mathrm{E}-\mathrm{E}_{389}$-expressing CaOV-3 cells $\left(\mathrm{t}_{1 / 2} \sim 7.6 \mathrm{~h}\right.$ ) by approximately 2 -fold (Figure $\left.4 \mathrm{~A}\right) . \mathrm{D}_{3} \mathrm{E}^{-\mathrm{E}_{389}}$ expression produced a similar stabilization of Sox 9 mRNA $\left(\mathrm{t}_{1 / 2} \sim 7.5 \mathrm{~h}\right)(4.7$-fold) (Figure 4B). These results suggest that $\mathrm{p} 70^{\mathrm{s} 6 \mathrm{~K}}$ may interfere with the mRNA degradation pathway to stabilize Twist and Sox9 mRNAs, leading to their accumulation.

\section{$\mathrm{p}^{70^{\mathrm{S} 6 \mathrm{~K}}}$ directly targets miR-145 to increase Twist and Sox9 expression}

Given the importance of $\mathrm{p} 70^{\mathrm{s} 6 \mathrm{~K}}$ in mediating Twist and Sox9 mRNA half-lives, we were particularly interested in miRNAs that have been demonstrated to function in these processes [21]. To address this question, we employed a systematic approach to identify such miRNA regulators which should have the ability to bind the Twist and Sox9 mRNAs. We first compared the set of miRNAs predicted to target Twist and/or Sox 9 3'UTR using miRNAmap 2.0 which employs a variety of prediction databases (Target Scan program, miRanda algorithm, and RNAhybrid program). The analysis, followed by examination of the set of miRNAs known to be associated with ovarian cancer progression [22-24], revealed 17 miRNAs (let-7b, miR-10b, miR-105, miR127, miR-133a, miR-145, miR-147, miR-154, miR-199a, miR-199b, miR-214, miR-299, miR-302c, miR-331, miR-337, miR-376, miR-424) to target either Twist and/ or Sox9 mRNAs and also present at lower levels in the metastatic progression of ovarian cancer. Among these miRNAs, interestingly, only the expression of miR-145 was significantly repressed by the constitutively active $\mathrm{p} 70^{\mathrm{S} 6 \mathrm{~K}}$ and increased by the $\mathrm{p} 70^{\mathrm{S} 6 \mathrm{~K}}$ siRNA as compared to their respective empty vector and nonspecific siRNA controls (Figure 5A). These results suggest that $\mathrm{p} 70^{\mathrm{S} 6 \mathrm{~K}}$ promotes the expression of specific miRNAs.

In order to verify whether Twist and Sox9 are directly targeted by miR-145, we examined the effect of 
A
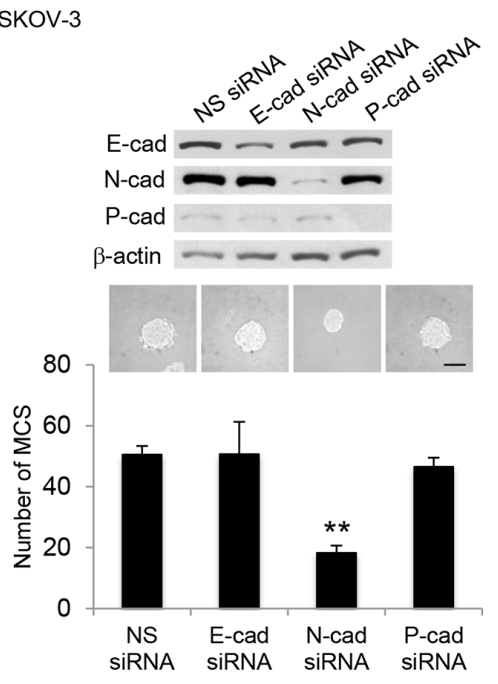

B sKov-3

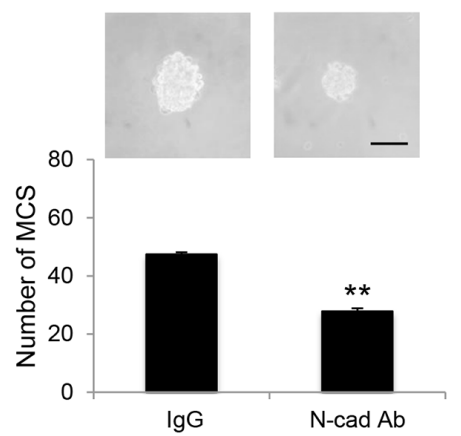

C
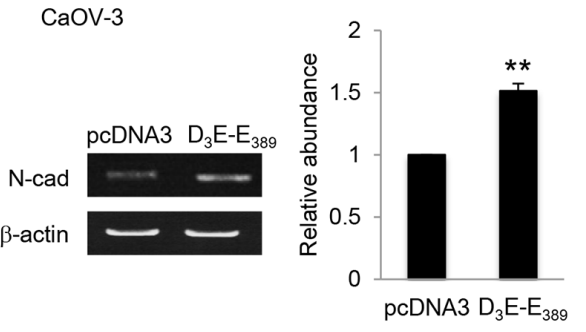

D

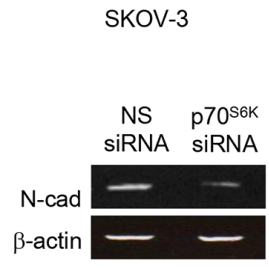

HEYA8

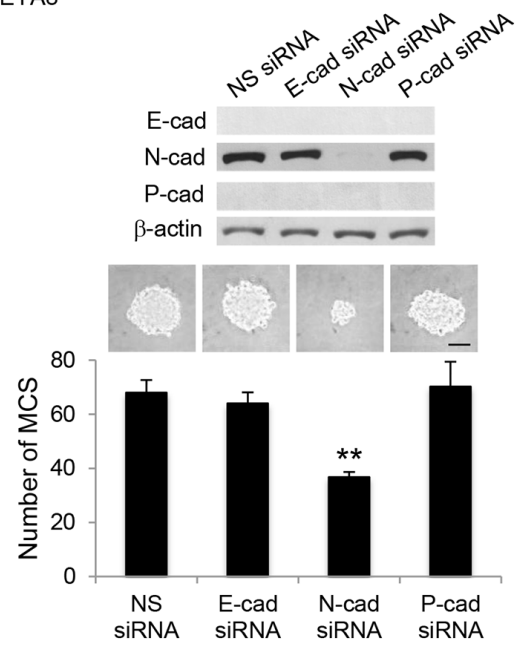

HEYA8
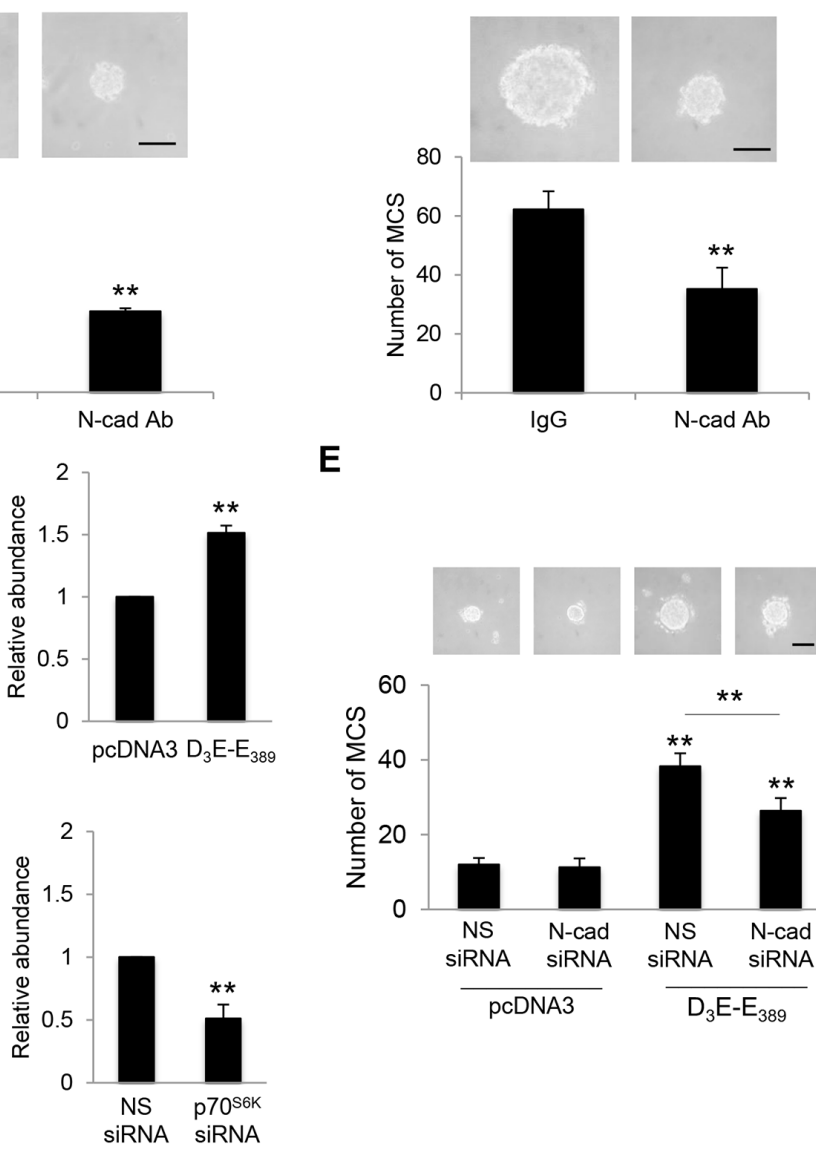

$\mathbf{E}$

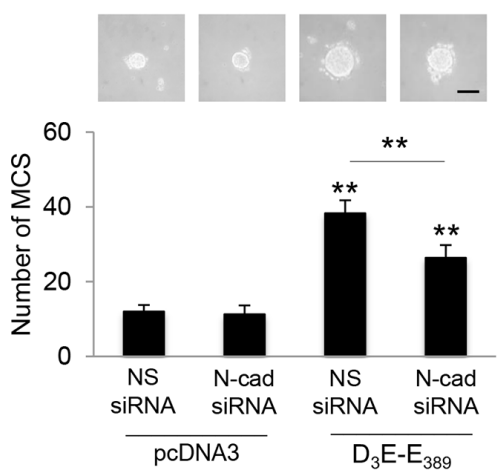

Figure 2: Silencing of N-cadherin abolishes MCS formation. A. SKOV-3 or HEYA8 were transfected with nonspecific (NS) siRNA, E-cadherin siRNA, N-cadherin siRNA or P-cadherin siRNA. Expression of E-cadherin, N-cadherin and P-cadherin were assessed by Western blotting. $\beta$-actin was included as a loading control. The band intensities were quantified by densitometric analysis and expression levels relative to that of $\beta$-actin were indicated. The number of tumor spheres generated in were photographed and counted. B. SKOV-3 or HEYA8 cells were incubated with IgG or N-cadherin function blocking antibody for $72 \mathrm{hr}$. The number of tumor spheres generated was photographed and counted. C. CaOV-3 cells were transfected with pcDNA3 or constitutively active p $70^{\mathrm{S} 6 \mathrm{~K}}\left(\mathrm{D}_{3} \mathrm{E}-\mathrm{E}_{389}\right)$ or D. SKOV-3 cells were transfected with NS siRNA or $770^{\mathrm{S} 6 \mathrm{~K}}$ siRNA for $72 \mathrm{hr}$. Total RNA was extracted and reverse transcription-PCR was performed using $\mathrm{N}$-cadherin sequence-specific primers. $\beta$-actin was included as a control. The band intensities were quantified by densitometric analysis and expression levels relative to that of $\beta$-actin are indicated. E. $\mathrm{CaOV}-3$ cells were transfected with pcDNA3 or $\mathrm{D}_{3} \mathrm{E}-\mathrm{E}_{389}$ in the presence of NS siRNA or N-cadherin siRNA for $72 \mathrm{hr}$. The number of tumor spheres generated was photographed and counted. Bar $=100 \mu \mathrm{m}$. Results are presented as the mean $\pm \mathrm{SD}$ and were analyzed using paired student's $t$ test. ${ }^{* *} P<0.005$, compared with NS siRNA, IgG or pcDNA3. 
miR-145 on the expression of Twist and Sox9 through heterologous luciferase reporter assays. As shown, miR145 was able to repress the luciferase activity of reporter containing the 3' untranslated regions (UTR) of both Twist and Sox9, revealing Twist and Sox 9 to be directly targeted by miR-145 (Figure 5B). Consistent with the phenotypes of its target genes, addition of pre-miR-145 abrogated $\mathrm{D}_{3} \mathrm{E}_{-} \mathrm{E}_{389}$-mediated MCS formation, whereas addition of anti-miR-145 reversed the suppression of MCS formation resulting from $\mathrm{p} 70^{\mathrm{S} 6 \mathrm{~K}}$ knockdown, indicating that miR-145 is necessary for the promotion of MCS (Figure 5C). To investigate whether the potential regulation of miR-145
A CaOV-3
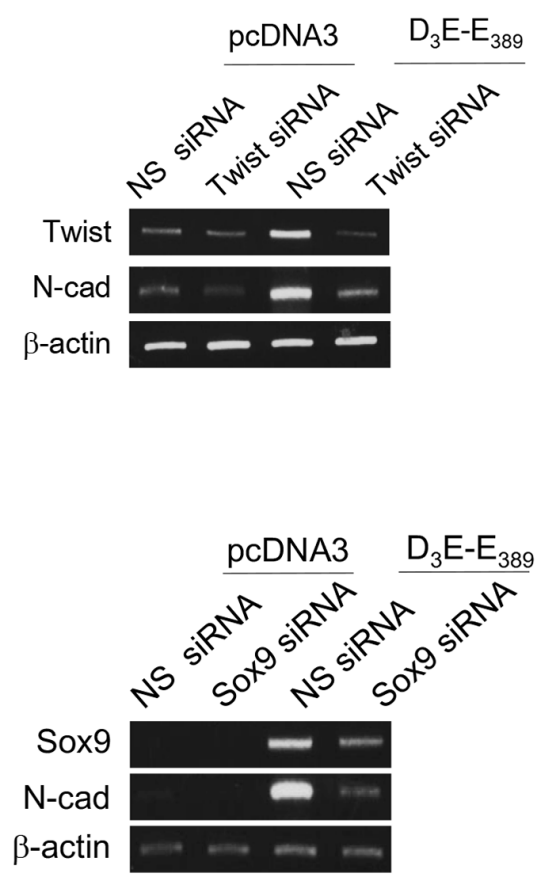

\section{B CaOV-3}

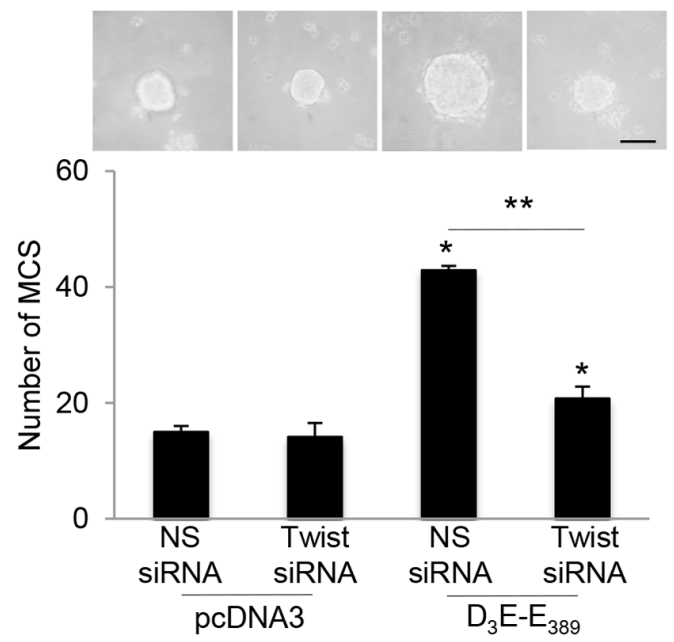

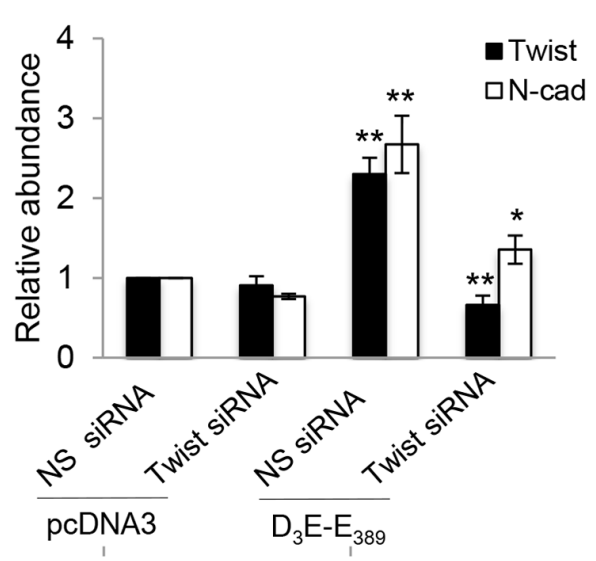
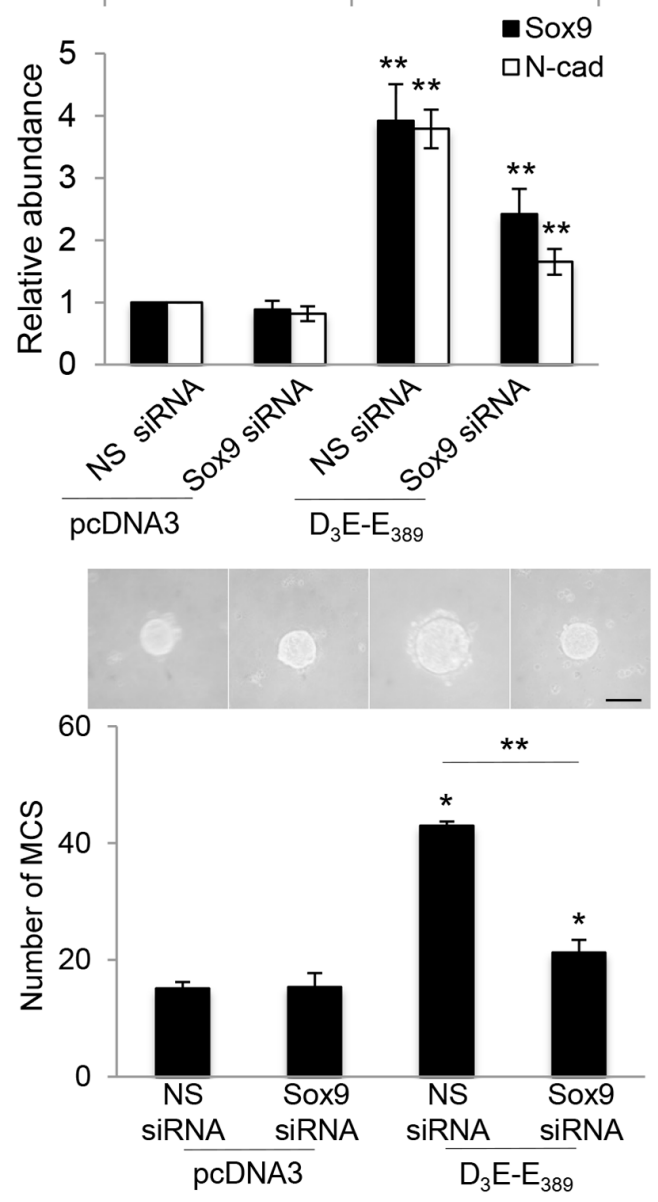

Figure 3: $\mathbf{p 7 0}^{\mathrm{s} 6 \mathrm{~K}}$ increases expression of Twist and Sox9 transcription factors. A. CaOV-3 transfected with pcDNA3 or constitutively active $\mathrm{p} 70^{\mathrm{S} 6 \mathrm{~K}}\left(\mathrm{D}_{3} \mathrm{E}-\mathrm{E}_{389}\right)$ in the presence of nonspecific (NS) siRNA or Twist siRNA or Sox9 for $72 \mathrm{hr}$. Total RNA was extracted and reverse transcription-PCR was performed using Twist, Sox 9 , and N-cadherin sequence-specific primers. The signal intensities were quantified by densitometric analysis and expression levels relative to that of $\beta$-actin are indicated. B. The number of tumor spheres generated was photographed and counted. Bar $=100 \mu \mathrm{m}$. Results are presented as the mean \pm SD and were analysed using paired student's $t$ test. $* P<0.05 ; * * P<0.005$, compared with pcDNA3 or NS siRNA. 
on Twist and Sox9 also correlated with MCS formation potential, we compared the levels of miR-145 with the expression levels of Twist and Sox9. We observed that SKOV-3 and HEYA8 showing little or no miR-145 also expressed high levels of Twist and Sox9 (Figure 5D). Expression of N-cadherin which determines the ability to form MCS was significantly more frequent in SKOV-3 and HEYA8 than CaOV-3 (Figure 5E).

\section{A specific role for Dicer microprocessor in miR- 145 turnover}

To determine how $\mathrm{p} 70^{\mathrm{s} 6 \mathrm{~K}}$ regulates miR-145 expression, we assessed different aspects of miR-145 expression in response to $\mathrm{p} 70^{\mathrm{S} 6 \mathrm{~K}}$. Despite the increases in mature miR-145 expression, no significant changes were observed in primary miR-145 levels following p $70^{\mathrm{s} 6 \mathrm{~K}}$ siRNA as determined by RT-PCR (Figure 6A). Furthermore, it has also been shown that its downregulation observed in various tumors is not due to DNA copy number loss $[24,25]$, suggesting that $\mathrm{p} 70^{\mathrm{S} 6 \mathrm{~K}}$ may post-transcriptionally regulate miR-145 expression. One post-transcriptional mechanism by which $\mathrm{p} 70^{\mathrm{S} 6 \mathrm{~K}}$ could possibly downregulate the levels of mature miR145 is by suppressing the maturation of miR-145. Previous reports have demonstrated that Dicer serves as a major regulator of the miRNA biogenesis machinery [26]. Knocking down Dicer clearly abolished the $\mathrm{p} 70^{\mathrm{S} 6 \mathrm{~K}} \mathrm{siRNA}-$ mediated suppression of MCS formation (Figure 6B), suggesting a novel link between $\mathrm{p} 70^{\mathrm{S} 6 \mathrm{~K}}$ and Dicer in MCS

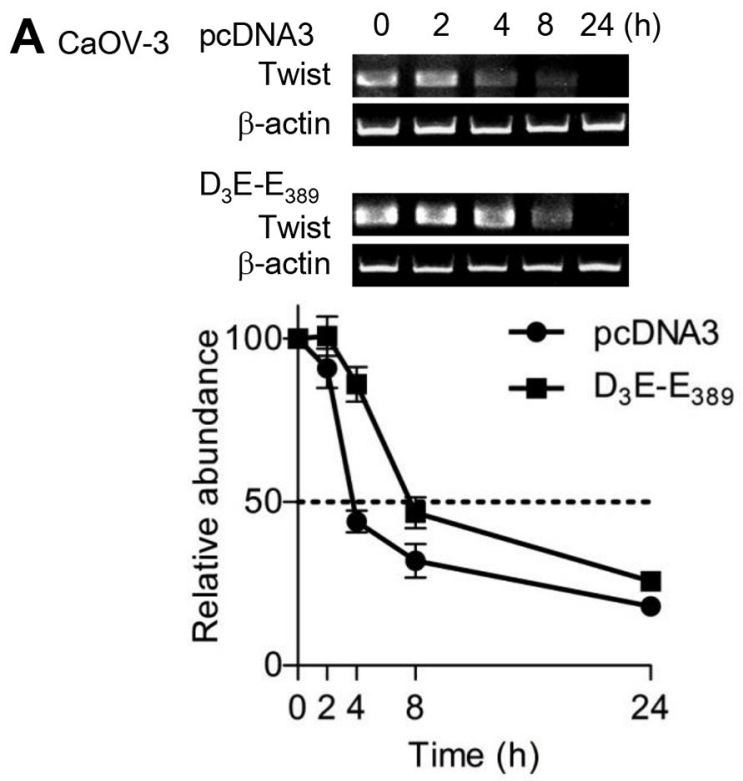

formation and warrants a closer examination into the mechanism through which $\mathrm{p} 70^{\mathrm{S} 6 \mathrm{~K}}$ regulates Dicer.

\section{p70 $^{\mathrm{s} 6 \mathrm{~K}}$ impairs the interaction of TTP with Dicer}

We first examined the potential regulation of $\mathrm{p} 70^{\mathrm{s} 6 \mathrm{~K}}$ on Dicer expression, but found no effect (Figure 6C), suggesting that $\mathrm{p} 70^{\mathrm{S} 6 \mathrm{~K}}$ may regulate Dicer via its interacting partners. The recruitment of AU-rich RNAbinding protein (ARE-BP), KH-type splicing regulatory protein (KSRP), to Dicer is critical for loading miRNA precursors onto the microprocessor complex and facilitating miRNA maturation from precursor to mature miRNAs [27]. However, we found no similar interaction between KSRP and Dicer upon $\mathrm{p} 70^{\mathrm{S} 6 \mathrm{~K}}$ activation (Figure 6D). Thus we investigated whether other members of ARE-BPs may physically associate with Dicer. TTP displayed lower levels in the metastatic progression of ovarian cancer [28] albeit previously not known to interact with Dicer. Coimmunoprecipitation experiments showed that silencing of $\mathrm{p} 70^{\mathrm{S} 6 \mathrm{~K}}$ significantly enhanced the interaction of TTP with Dicer (Figure 6D), suggesting that TTP can bind Dicer.

\section{The miRNA destabilizing factor TTP is phosphorylated by $\mathbf{p}^{70^{\text {s6K }}}$}

Knockdown of TTP obtained using siRNA led to a more than $75 \%$ reduction in the steady-state level of miR145 (Figure 7A). Furthermore, Twist, Sox9, and N-cadherin mRNAs were stable in TTP siRNA-transfected cells

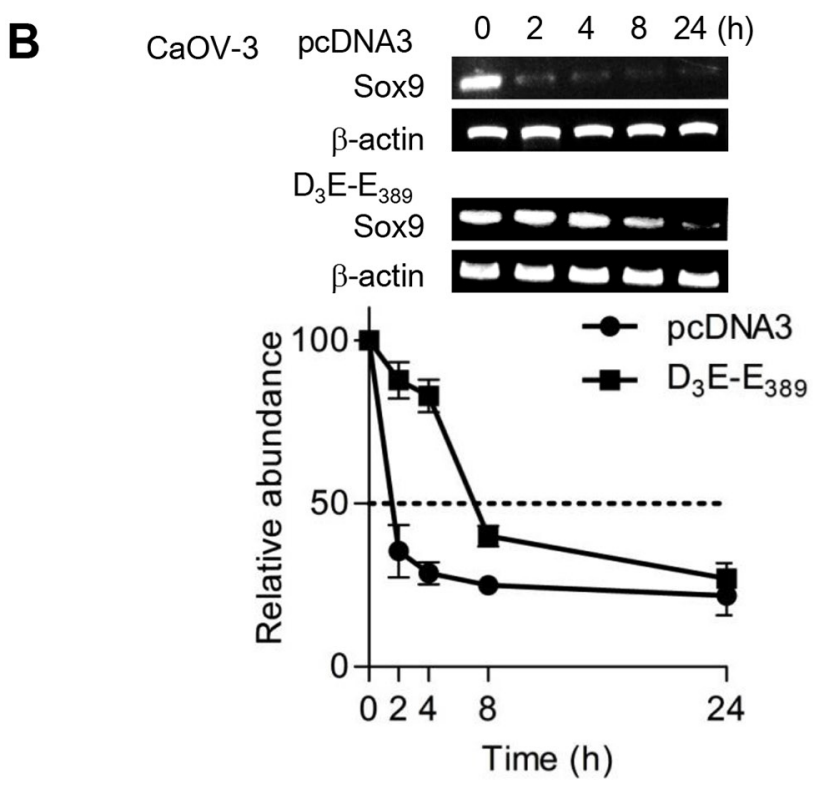

Figure 4: p70 $^{\mathrm{S} 6 \mathrm{~K}}$ enhances Twist and Sox9 mRNA stabilities. A. CaOV-3 cells transfected with pcDNA3 or $\mathrm{D}_{3} \mathrm{E}-\mathrm{E}_{389}$ were incubated with actinomycin D (ActD; $5 \mu \mathrm{g} / \mathrm{ml}$ ) over a time course of $0,2,4,8$ and $24 \mathrm{hr}$. Total RNA was then extracted and reverse transcription-PCR was performed using Twist and B. Sox9 sequence specific primers. $\beta$-actin was included as an internal control. Results are presented as the mean $\pm \mathrm{SD}$. 
A
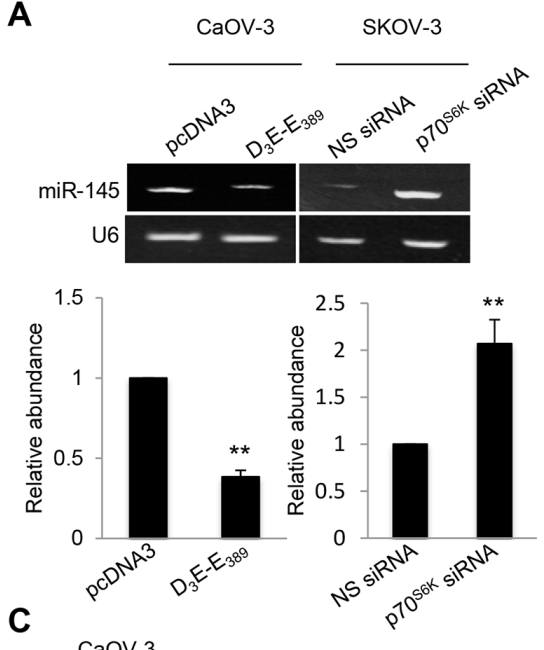

CaOV-3
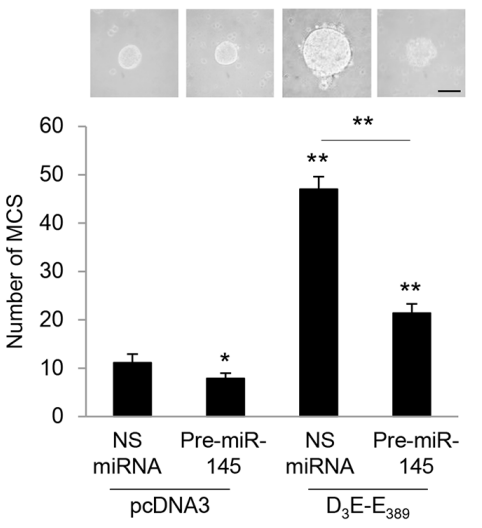

D

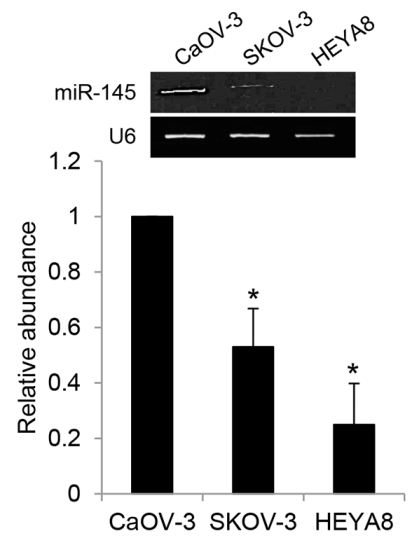

B
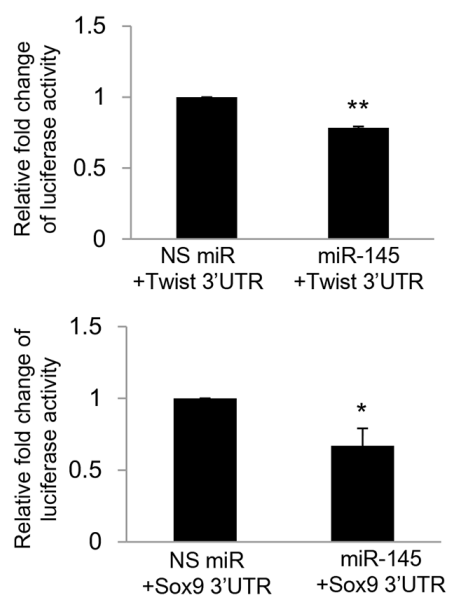

SKOV-3
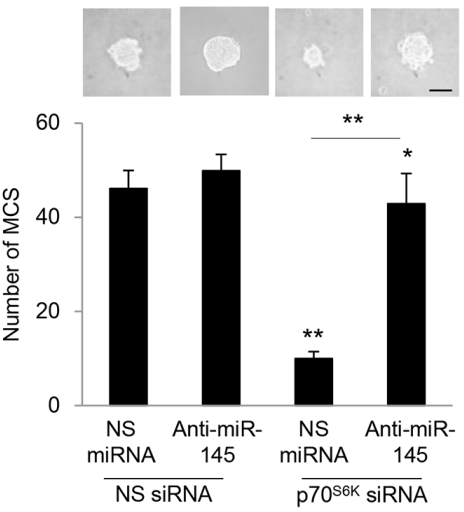

E

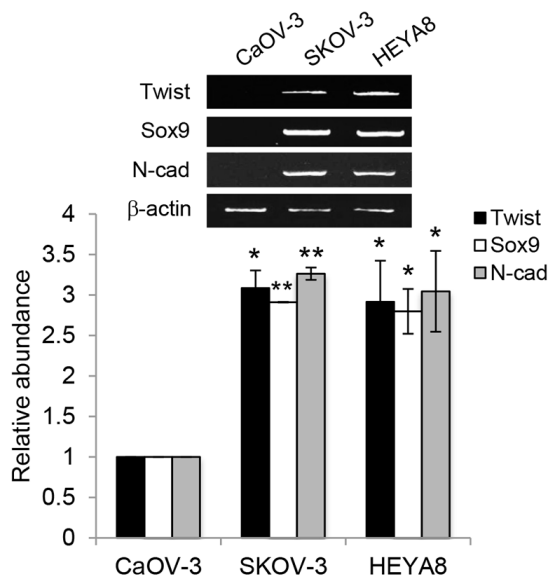

Figure 5: $\mathbf{p 7 0}^{\mathrm{S} 6 \mathrm{~K}}$ decreases Twist and Sox9 mRNA turnover via suppression of miR-145. A. CaOV-3 cells were transfected with pcDNA3 or constitutively active p $70^{\mathrm{s} 6 \mathrm{~K}}\left(\mathrm{D}_{3} \mathrm{E}-\mathrm{E}_{389}\right)$ or SKOV-3 cells were transfected with nonspecific (NS) siRNA or p $70^{\mathrm{s} 6 \mathrm{~K}}$ siRNA for $72 \mathrm{hr}$. Total RNA was extracted and reverse transcription-PCR was performed using mature miR-145 sequence-specific primers. U6 was included as an internal control. The signal intensities were quantified by densitometric analysis and the amounts were normalized for the amount of U6. B. CaOV-3 cells were transiently transfected with $0.5 \mu \mathrm{g}$ of the luciferase reporter gene fused with Twist 3'UTR or Sox9 3'UTR and $15 \mathrm{ng}$ of $\beta$-galactosidase plasmid for $72 \mathrm{hr}$. Luciferase and $\beta$-galactosidase activities were assayed, and the luciferase activity of each sample was normalized with $\beta$-galactosidase activity. $\mathbf{C}$. CaOV-3 cells were transfected with pcDNA3 or $\mathrm{D}_{3} \mathrm{E}_{-} \mathrm{E}_{389}$ in the presence of NS miRNA or precursor miR-145 (pre-miR-145) or SKOV-3 were transfected with NS siRNA or p70 $0^{\mathrm{S} 6 \mathrm{~K}}$ siRNA in the presence of NS miRNA or miR-145 inhibitor (anti-miR-145) for $72 \mathrm{hr}$. The number of tumor spheres generated was photographed and counted. Bar $=100 \mu \mathrm{m}$. D. CaOV-3, SKOV-3 and HEYA8 were cultured in non-adherent culture dish for $72 \mathrm{hr}$. Total RNA was extracted and reverse transcription-PCR was performed using sequence-specific primers to mature miR-145 (mat-miR-145). U6 was included as an internal control. E. Twist, Sox9, and N-cadherin sequence-specific primers. $\beta$-actin was included as an internal control. The signal intensities were quantified by densitometric analysis and the amounts were normalized for the amount of U6 or $\beta$-actin. Results are presented as the mean \pm SD and were analyzed using paired student's $t$ test. ${ }^{*} P<0.05$; ${ }^{*} P<0.005$, compared with NS siRNA, pcDNA3 or NS miRNA. 
(Figure 7B). Importantly, knockdown of TTP significantly restored the decreased MCS formation mediated by knockdown of $\mathrm{p} 70^{\mathrm{S} 6 \mathrm{~K}}$ (Figure $7 \mathrm{C}$ ). Together, these results indicate that TTP is crucial in controlling miR-145 maturation and, in turn, Twist/Sox9-mediated N-cadherin expression and MCS formation. The phosphorylation of RNA-binding proteins modulates their association with Dicer [29]. We further investigated whether $\mathrm{p} 70^{\mathrm{S} 6 \mathrm{~K}}$ was able to phosphorylate TTP. Using PhosphoNet (www. Phosphonet.ca/), a kinase substrate prediction database, TTP has been found to be a putative substrate for $\mathrm{p} 70^{\mathrm{S} 6 \mathrm{~K}}$ (Figure 7D). Knockdown of $\mathrm{p} 70^{\mathrm{S} 6 \mathrm{~K}}$ significantly reduced the phosphorylation of TTP while not empty vector control, as shown by anti-TTP immunoprecipitation following phospho-serine detection (Figure 7D), suggesting that $\mathrm{p} 70^{\mathrm{S} 6 \mathrm{~K}}$ is a novel upstream regulator of the TTP.

\section{$\mathrm{p}^{70^{\mathrm{S} 6 \mathrm{~K}}}$ and its associated signaling in human ovarian carcinoma}

To understand more about the clinical relationship between $\mathrm{p} 70^{\mathrm{s} 6 \mathrm{~K}}$ and TTP levels in ovarian tumors, we used the publicly available datasets from Oncomine (available at: https://www.oncomine.org) to survey a large number of ovarian cancers. There was a significant inverse association between $\mathrm{p} 70^{\mathrm{s} 6 \mathrm{~K}}$ and TTP levels, in

\section{A}

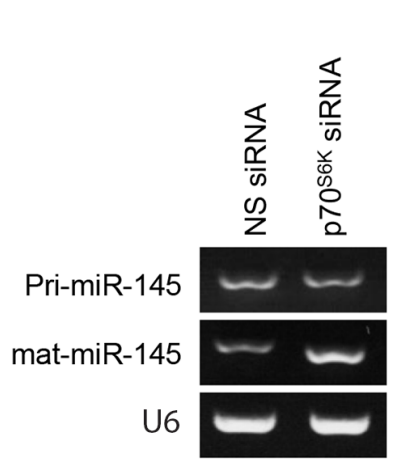

C

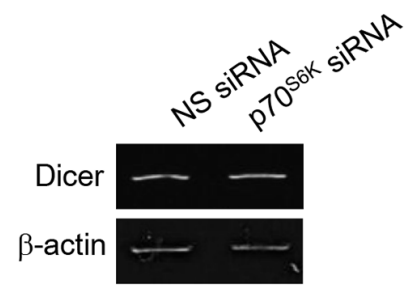

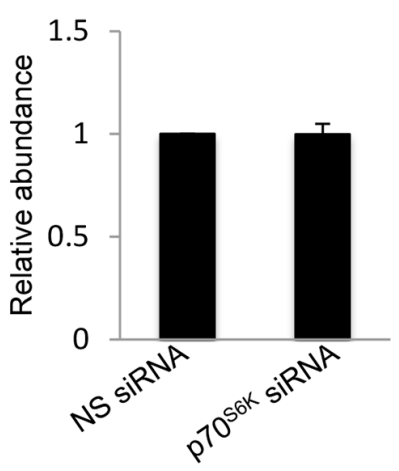

B

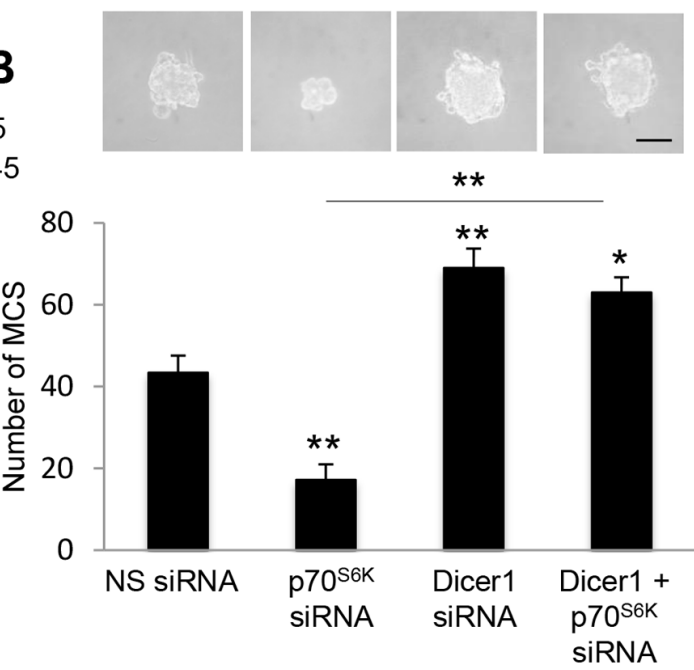

D

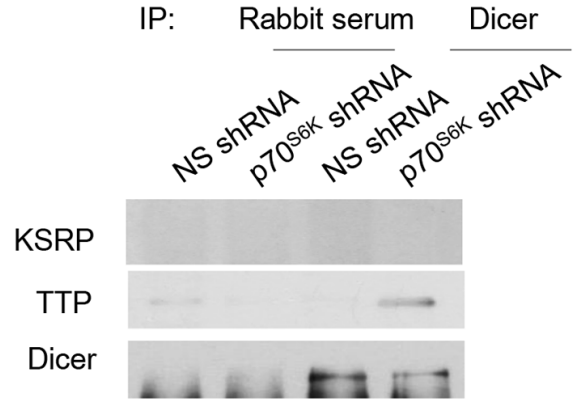

Figure 6: $\mathbf{p 7 0}{ }^{\mathrm{s} 6 \mathrm{~K}}$ downregulates mature miR-145 but not primary miR-145. A. SKOV-3 cells were transfected with nonspecific (NS) siRNA or $\mathrm{p} 70^{\mathrm{S} 6 \mathrm{~K}}$ siRNA for $72 \mathrm{hr}$. Total RNA was extracted and reverse transcription-PCR was performed using sequence-specific primers to primary miR-145 (pri-miR-145) and mature miR-145 (mat-miR-145). U6 was included as an internal control. The signal intensities were quantified by densitometric analysis and the amounts were normalized for the amount of U6. B. SKOV-3 cells were transfected with NS siRNA, p70 ${ }^{\mathrm{S} 6 \mathrm{~K}}$ siRNA, or Dicer siRNA for $72 \mathrm{hr}$. The number of tumor spheres generated was photographed and counted. C. SKOV-3 cells were transfected with nonspecific (NS) siRNA or p70 ${ }^{\mathrm{s} 6 \mathrm{~K}}$ siRNA for $72 \mathrm{hr}$. Total RNA was extracted and reverse transcription-PCR was performed using Dicer sequence-specific primers. $\beta$-actin was included as an internal control. The signal intensities were quantified by densitometric analysis and expression levels relative to that of $\beta$-actin are indicated. D. p70 ${ }^{\mathrm{S} 6 \mathrm{~K}}$ siRNA-transfected SKOV-3 cells were immunoprecipitated with Dicer antibody. Rabbit serum was used as a control. The immunocomplex was resolved using Western blotting and detected with KSRP and TTP antibodies. Bar $=100 \mu \mathrm{m}$. Results are presented as the mean \pm SD and were analyzed using paired student's $t$ test. ${ }^{*} P<0.05 ; * * P<0.005$, compared with NS siRNA. 

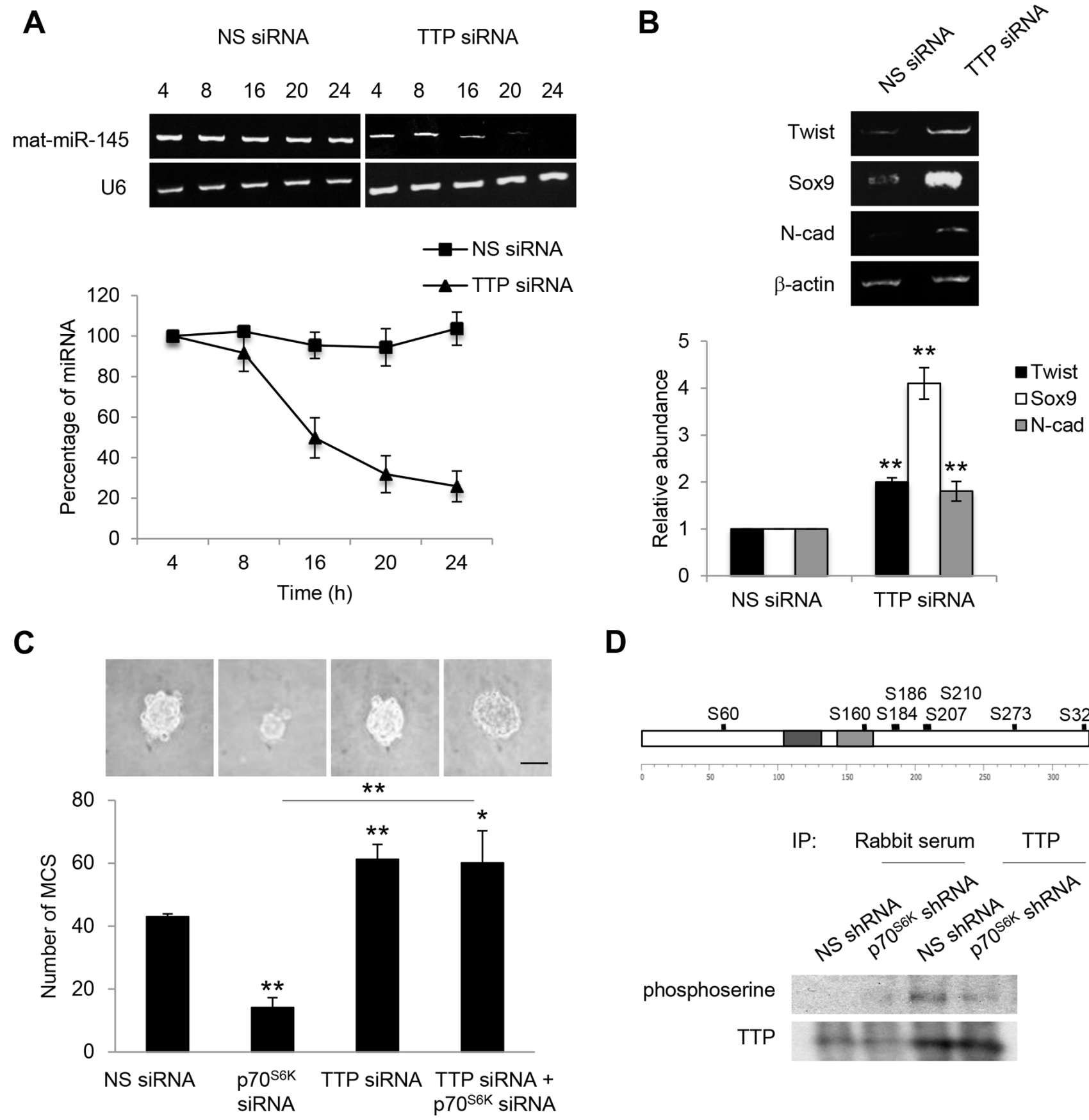

D
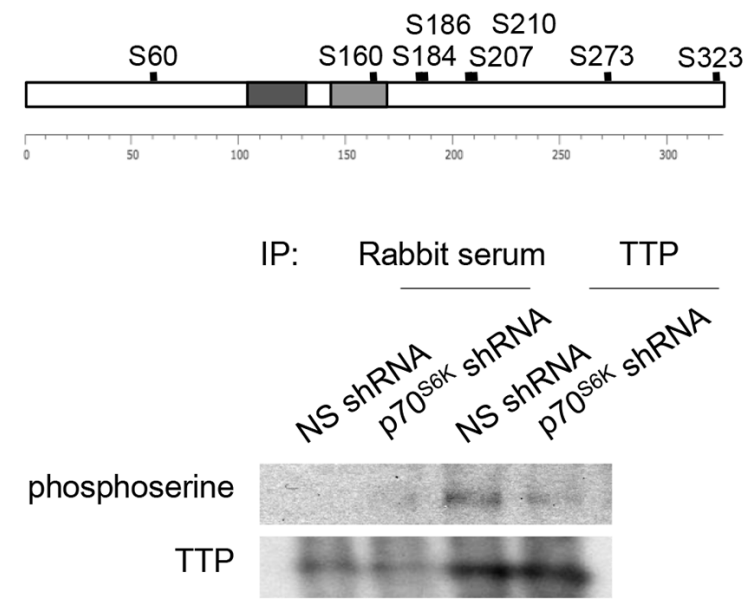

Figure 7: TTP increases the level of mature miR-145. A. SKOV-3 cells were transfected with nonspecific (NS) siRNA or TTP siRNA over a time course of 4, 8, 16, 20 and $24 \mathrm{hr}$. Total RNA was extracted and reverse transcription-PCR was performed using sequence-specific primers to mature miR-145 (mat-miR-145). U6 was included as an internal control. The signal intensities were quantified by densitometric analysis and the amounts were normalized for the amount of U6. B. Reverse transcription-PCR was also performed using sequence-specific primers to Twist, Sox 9 and N-cadherin. $\beta$-actin was included as an internal control. The signal intensities were quantified by densitometric analysis and expression levels relative to that of $\beta$-actin are indicated. C. SKOV-3 cells were transfected with NS siRNA, p70 ${ }^{\mathrm{S} 6 \mathrm{~K}}$ siRNA or TTP siRNA for $72 \mathrm{hr}$. The number of tumor spheres generated was photographed and counted. D. In silico analysis of the TTP phosphorylation sites were performed using the Human Phosphosite Knowledgebase available at PhosphoNet (http://www.phosphonet.ca/). Phosphorylation sites with a Kinase Predictor score greater or equal to 350 were indicated. $\mathrm{p} 70^{\mathrm{S} 6 \mathrm{~K}}$-stable knockdown SKOV-3 cells were immunoprecipitated with TTP antibody. Rabbit serum was used as a control. The immunocomplexes were resolved using Western blotting and detected by a phosphoserine antibody. Bar $=100 \mu \mathrm{m}$. Results are presented as the mean \pm SD and were analyzed using paired student's $t$ test. $* P<0.05 ; * * P<0.005$, compared with NS siRNA or $\mathrm{p} 70^{\mathrm{s} 6 \mathrm{~K}}$ siRNA. 
which $\mathrm{p} 70^{\mathrm{s} 6 \mathrm{~K}}$ was highly expressed in tumor samples whereas TTP was suppressed (Figure 8A). Next, we transplanted nonspecific miRNA and precursor miR-145 MCS cells into the peritoneum of NOD/SCID mice to determine whether miR-145 activation actually produced a less malignant phenotype in vivo. The results showed that highly aggressive tumors with visible tumor masses growing on the omentum, mesenteries, and small bowels with developed ascites reflecting characteristics commonly displayed by ovarian cancer lesions were observed in mice transplanted with nonspecific miRNA (Figure 8B). In contrast, the number and the size of tumor nodules and ascites volume were substantially decreased by treatment with precursor miR-145 (Figure 8B). These studies suggest that $\mathrm{p} 70^{\mathrm{S} 6 \mathrm{~K}}$ and its associated signaling may represent useful targets for the treatment of aggressive cell characteristics of ovarian cancer in vivo.

\section{DISCUSSION}

Metastatic progression requires effectors proteins associated with the same cellular phenotype to be coherently expressed. In recent years, posttranscriptional regulation has emerged as a robust regulation of coordinated gene expression and phenotype manifestation. The most studied of which is small noncoding miRNAs. In this study, we show for the first time that $\mathrm{p} 70^{\mathrm{s} 6 \mathrm{~K}}$, which is frequently hyperactive in human ovarian cancer [11], as a novel component of the miRNA biogenesis machinery, which governs post-transcriptional maturation of a subset of miRNAs, and that this regulation is important in effecting MCS formation.

As a key kinase in the control of target mRNA translation, $\mathrm{p} 70^{\mathrm{S} 6 \mathrm{~K}}$ is logically considered to be a modulator of protein synthesis. Here we provide the first demonstration that $\mathrm{p} 70^{\mathrm{S} 6 \mathrm{~K}}$, a key kinase in the control of target mRNA translation, can regulate miRNA biogenesis. This role of $\mathrm{p} 70^{\mathrm{s} 6 \mathrm{~K}}$ in the miRNA-generating complex regulation is one of the most important and exciting emerging paradigms, which may link its multiple facets of cell activities seen [10], and its therapeutic inhibition displays in vivo efficacy highlights the significance of $\mathrm{p} 70^{\mathrm{s} 6 \mathrm{~K}}$ as a key promoter of ovarian metastatic progression.

The regulation of miRNA remains still largely unknown. Clearly, transcriptional regulation is an essential control. Alternatively, the posttranslational modification
A

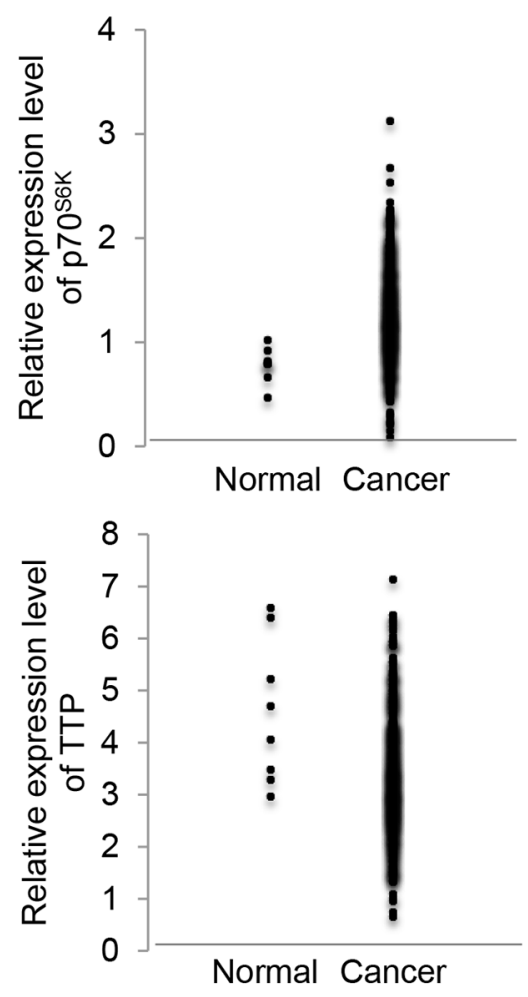

B
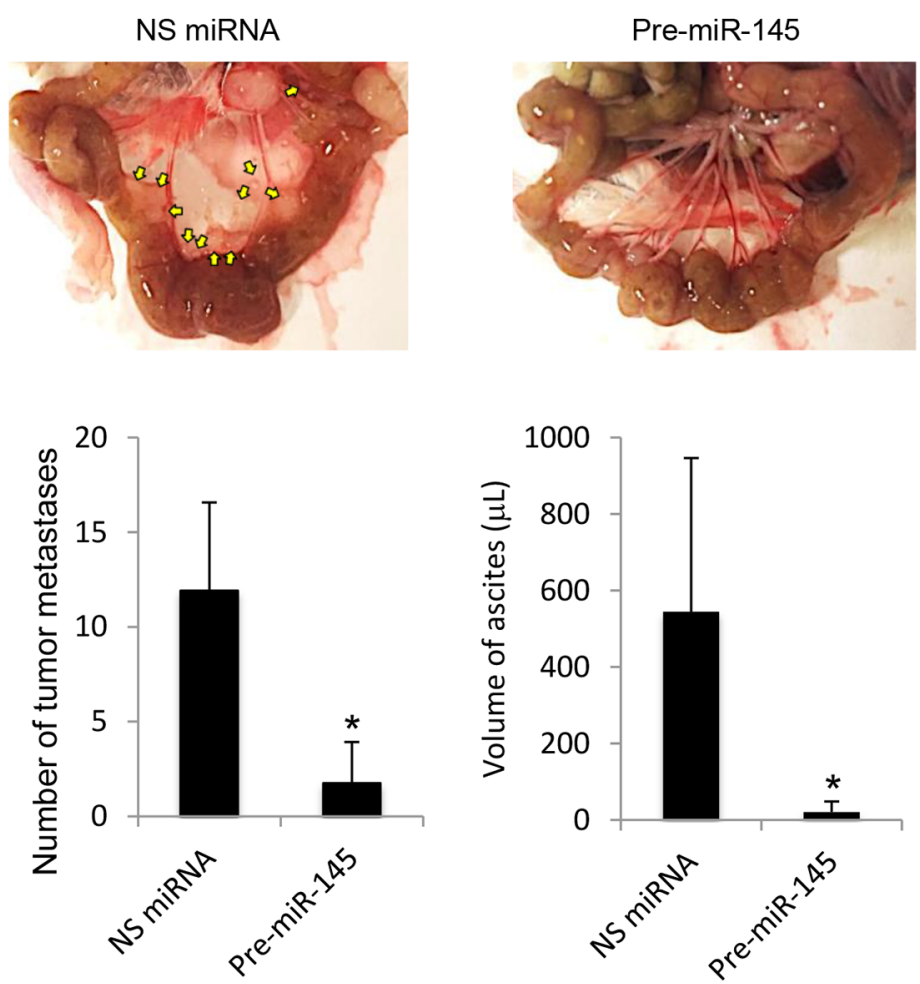

Figure 8: $\mathrm{p}^{\mathrm{S}} 0^{\mathrm{S} 6 \mathrm{~K}}$ and TTP expression in human ovarian cancers and miR-145 upregulation results in decreased cancer progression in vivo. A. Clinical data were retrieved from the TCGA Ovarian dataset which contains 594 samples available on Oncomine (https://www.oncomine.org). B. NOD/SCID mice were intraperitoneally injected with SKOV-3 cells transduced by nonspecific (NS) miRNA or precursor miR-145 (pre-miR-145). At the time of sacrifice, the peritoneal cavity was assessed for evidence of metastases. The metastatic lesions were excised and their total number was counted, and ascites volume was measured. Results are presented as the mean \pm SD. $* P<0.05$ compared with NS miRNA. 
of miRNAs, albeit less studied, has recently garnered much attention as an important regulatory mechanism of miRNA activities. Various kinases, such as p38 MAPK, Akt, and ATM have been shown to phosphorylate KSRP of the miRNA-generating complex at different residues and regulate its biological activities [30,31]. This study is the first to demonstrate that TTP, an ARE-BP that has been widely studied for posttranscriptional gene regulation and miRNA biogenesis [27], is a substrate of $\mathrm{p} 70^{\mathrm{S} 6 \mathrm{~K}}$, adding $\mathrm{p} 70^{\mathrm{s} 6 \mathrm{~K}}$ as a new member of posttranscriptional modulators of miRNAs, and TTP as a new protein interactor of Dicer. In accordance with our findings, while changes in the expression level of Dicer was not frequently observed in ovarian cancer tissues [24], TTP loss is found in many types of cancers including ovarian cancer and this downregulation correlates with increased metastatic potential and poor prognosis [28, 32-34]. Although it is possible that TTP may disrupt the global translation of all miRNAs, our existing data suggest that not all miRNAs are targets of TTP. Likewise, a G-rich motif in precursor miRNAs has been identified as a critical regulatory element in KSRP, an ARE-BP-mediated miRNA maturation, suggesting regulation specificity of ARE-BP on miRNA maturation [35].

Little is known about the regulation of N-cadherin. Here we show for the first time that miR-145 divergently targets Twist and Sox9 and comprise a coordinated network that maximally enhances $\mathrm{N}$-cadherin signaling. Consistently, seeding regions of miR-145 has been identified in 461-488 of the Twist 3'UTR (NG_008114.1) and 265-289 of the Sox9 3'UTR (NG 012490.1). The simultaneous targeting of multiple genes for metastasis promotion by a single metastasis suppressor miRNA may explain the dramatic effects observed [36], highlighting the significance of miR-145 as a key tumor suppressor of ovarian cancer progression. Indeed, miR-145 is one of the most frequently studied miRNAs detected in human cancers, and it has been validated to be downregulated in ovarian cancer [22]. miR-145 downregulation is associated with ovarian cancer progression and that low miR-145 expression correlates with poor survival [37]. It is also relevant to the clinical situation that Twist and Sox 9 are often elevated in malignant ovarian tumors and Twist expression confers a poor outcome to the late stage ovarian cancer patient survival $[19,20]$.

The importance of miRNAs in cancer biology has opened avenues for drug development based on the inhibition of oncomiRs or replacement of suppressor miRNAs [38, 39]. The advantage of using miRNA approaches is based on its ability to simultaneously target multiple genes that may be involved in coregulating a given function. Traditional gene therapy is hindered by inefficient delivery of large encoding gene into the nucleus. On the contrary, miRNAs are small in size and active in cytoplasm [40]. Liposome-based nano-sized carrier-mediated miRNA delivery constitutes a promising nanomedicine approach in cancer therapy. Indeed, the safety and efficacy of miR-34 liposomal injection is undergoing Phase I clinical trials on liver, lung, renal cell carcinomas, and other hematologic malignancies (NCT01829971, https://clinicaltrials.gov/ct2/show/ NC T01829971?term=NCT01829971\&rank=1). The closed space of the peritoneal cavity may offer an advantage for gene transfer in that the therapeutic genes can be sensitive and specific to the target cells.

Deregulation of $\mathrm{p} 70^{\mathrm{S} 6 \mathrm{~K}}$ signaling frequently occurs in many human cancers, and it appears to play an important role in their progression. For example, active $\mathrm{p} 70^{\mathrm{S} 6 \mathrm{~K}}$-expressing breast cancer has a worse prognosis [41]. Furthermore, p $70^{\mathrm{S} 6 \mathrm{~K}}$ overexpression in breast, colon, liver, and ovarian tumors are found to be related to aggressive malignant phenotypes [11, 42-44], suggesting that the role of $\mathrm{p} 70^{\mathrm{s} 6 \mathrm{~K}}$ in MCS that we propose in ovarian cancer may be extended to other tumor cell types and thereby $\mathrm{p} 70^{\mathrm{S} 6 \mathrm{~K}}$ could be an attractive target for therapeutics. Despite the fact that many PI3K pathway inhibitors have been developed, the clinical trials with these drugs have not been promising due to crosstalk with multiple pathways and the presence of potent feedback loops [45]. Targeting $\mathrm{p} 70^{\mathrm{S} 6 \mathrm{~K}}$ may thus represent a potential therapeutic advantage over current PI3K inhibitors, which might prove to be more effective and specific while minimizing toxicity. Moreover, the addiction of many tumors to the pathway provides a rationale for PI3K/Akt target, particularly $\mathrm{p} 70^{\mathrm{S} 6 \mathrm{~K}}$, exploitation.

In summary, we have established a novel regulatory link between $\mathrm{p} 70^{\mathrm{S} 6 \mathrm{~K}}$ and miRNA biogenesis that not only highlights a new mechanism through which $\mathrm{p} 70^{\mathrm{S} 6 \mathrm{~K}}$ functions to establish its pro-tumor regimen but also defines the MCS properties. These findings introduce a new dimension to our existing knowledge of the regulation of miRNA machinery and signaling molecules that remains to be explored by which can be exploited as more precise targets for therapy. The prominent role of $\mathrm{p} 70^{\mathrm{S} 6 \mathrm{~K}}$ in a broad range of human cancers suggests that its targeting may have key roles, not only in ovarian cancer, but also in other tumors.

\section{MATERIALS AND METHODS}

\section{Cell culture and treatments}

The human epithelial ovarian cancer cell lines SKOV-3, CaOV-3, and A2780 were gifts from Dr. N. Auersperg (University of British Columbia, Vancouver, B. C., Canada). HEYA8 was a gift from Dr. J. Liu (MD Anderson Cancer Center, Houston, TX). Cells were routinely grown in medium 199:MCDB 105 (1:1) (Sigma, St. Louis, MO) with $10 \%$ fetal bovine serum (Hyclone, Logan, UT) and $1 \%$ penicillin-streptomycin mixture (Invitrogen, Carlsbad, CA) in a humidified 95\% air, 
$5 \% \mathrm{CO}_{2}$ incubator at $37^{\circ} \mathrm{C}$ before experiments. MCS were generated by liquid overlay method [46]. Briefly, 5,000 cells $/ \mathrm{ml}$ were plated into dishes coated with $0.5 \%$ agarose (Invitrogen, Carlsbad, CA) (non-adherent culture conditions) for $72 \mathrm{~h}$ after treatment. The number of MCS generated with $\geqq 100 \mu \mathrm{m}$ diameter was counted. Mature miR-145 mimic were purchased from Ambion (Austin, TX). Synthetic oligos, mock with no homology to human genome, were used as a negative control. $\mathrm{p} 70^{\mathrm{S} 6 \mathrm{~K}}$ siRNA, Twist siRNA, Sox9 siRNA were acquired from Dharmacon (Lafayette, CO). miRNA or siRNA duplex were transfected into cells by using Lipofectamine 2000 according to the manufacturer's protocol (Invitrogen, Carlsbad, CA).

\section{Measurement of mRNA stability}

The half-life of Twist and Sox9 mRNAs were determined using actinomycin D chase experiments, following a standard protocol described elsewhere [47]. Briefly, actinomycin D was added to a final concentration of $5 \mu \mathrm{g} / \mathrm{ml}$ to block further transcription. At $0,2,4,8$, and $24 \mathrm{hr}$ after actinomycin D treatment, the cells were harvested, and mRNA was quantified by PCR as described above. The percentages of mRNA over time before and after the addition of actinomycin $\mathrm{D}$ were determined.

\section{Reverse transcription-polymerase chain reaction}

Total RNA was isolated by Trizol (Invitrogen, Carlsbad, CA). For detecting miR-145 levels, RNA was reversed transcribed to cDNA by TaqMan miRNA assays (Applied Biosystems, Foster City, CA) using specific stem-loop reverse transcription primer (5'-GTTGGCTCTGGTGCAGGGTCCGAGG TATTCGCACCAGAGCCAACAGGAT-3). The expression levels of mature miR-145 was quantified by PCR using sequence specific primers (Forward: 5'-CGGCAGGTCAAAAGGGTCCT-3'; Reverse: 5'-TG CAGG GTCCGAGGTATTCG-3'). Endogenous U6 small nuclear RNA levels were determined simultaneously for normalization.

\section{miRNA target prediction}

To define potential upstream regulators of Twist and Sox9, we matched candidate miRNAs that were predicted by using miRNAMap 2.0 (available at http://mirnamap.mbc. nctu.edu.tw/) which employs 3 publicly available algorithms, miRanda (http://www.microrna.org/microrna/home.do), TargetScan (http://www. targetscan.org/), and RNA hybrid (http://bibiserv.techfak.uni-bielefeld.de/rnahybrid).

\section{Western blot analysis}

Cell lysates $(20 \mu \mathrm{g}$ protein each) were separated by $7.5 \%$ SDS-polyacrylamide gel electrophoresis and transblotted onto nitrocellulose membrane (Bio-Rad). The membrane was blocked with 5\% nonfat dry milk and incubated with anti-phospho-p70 ${ }^{\mathrm{S} 6 \mathrm{~K}}$ (Thr389) $(1: 1,000)$ (Cell Signaling), anti-Twist $(1: 1,000)$ (Santa Cruz), anti-Sox9 $(1: 1,000)$ (Abcam), anti-N-cadherin $(1: 1,000)$ (Zymed), anti-E-cadherin $(1: 1,000)$ (BD Transduction Laboratories) in phosphate-buffered saline containing $0.1 \%$ Tween 20 rotating at $4{ }^{\circ} \mathrm{C}$ overnight. After washing, the membrane was further incubated with secondary antibodies coupled to horseradish peroxidase at room temperature for $1 \mathrm{~h}$ and developed with an enhanced chemiluminescent detection kit (Amersham).

\section{Luciferase reporter assay}

The putative miR-145 binding sites at the 3'UTR of Twist and Sox9 were cloned downstream of a cytomegalovirus promoter-driven firefly luciferase cassette in a vector. The $\beta$-galactosidase plasmid was cotransfected as internal control in the presence of either synthetic miR145 or mock control. Luciferase reporter assay (Promega, Madison, WI) was performed $72 \mathrm{hr}$ after transfection.

\section{In vivo intraperitoneal metastasis model}

All animal care and experimental procedures were carried out according to the Committee for the Use of Laboratory Animals of the University of Hong Kong approved protocols. SKOV-3 MCS $\left(2 \times 10^{5}\right.$ cells $)$ stably transduced with nonspecific miRNA or pre-miR-145 were injected intraperitoneally into 6- to 8-week-old female NOD/SCID mice (Charles River Laboratories, Wilmington, MA) ( $n=3$ mice per group, and the experiment was conducted twice). Mice were assessed weekly for signs of pain and discomfort, weight change, and ascites formation. At the time of sacrifice, the number of all visible $(>0.1 \mathrm{~cm}$ diameter) tumor nodules in the peritoneal cavity and the volume of ascites were assessed as evidence of metastases.

\section{Statistical analysis}

All experiments were carried out in triplicates and repeated at least two times with each experiment yielding essentially identical results. Data are presented as mean \pm S.D. Student's t-test and analysis of variance was performed in GraphPad Prism (GraphPad, San Diego, CA) to determine differences between the experimental groups and the control groups. A $P$-value less than 0.05 was regarded as statistically significant.

\section{ACKNOWLEDGMENTS}

This work was supported by the Hong Kong Research Grant Council General Research Fund (HKU782111) and the Collaborative Research Fund (CUHK8/CRF/11R). A.S.T.W. is Croucher Senior Research Fellow. 


\section{CONFLICTS OF INTEREST}

The authors declare that they have no conflicts of interest.

\section{REFERENCES}

1. Siegel RL, Miller KD and Jemal A. Cancer statistics, 2015. CA Cancer J Clin. 2014; 64:9-29.

2. Lengyel E. Ovarian cancer development and metastasis. Am J Pathol. 2010; 177:1053-1064.

3. Casey RC, Burleson KM, Skubitz KM, Pambuccian SE, Oegema TR, Jr., Ruff LE and Skubitz AP. Beta 1-integrins regulate the formation and adhesion of ovarian carcinoma multicellular spheroids. Am J Pathol. 2001; 159:2071-2080.

4. Shield K, Riley C, Quinn MA, Rice GE, Ackland ML and Ahmed N. Alpha2beta1 integrin affects metastatic potential of ovarian carcinoma spheroids by supporting disaggregation and proteolysis. J Carcinogen. 2007; 6:11.

5. Greenaway J, Moorehead R, Shaw P and Petrik J. Epithelialstromal interaction increases cell proliferation, survival and tumorigenicity in a mouse model of human epithelial ovarian cancer. Gynecol Oncol. 2008; 108:385-394.

6. Bapat SA, Mali AM, Koppikar CB and Kurrey NK. Stem and progenitor-like cells contribute to the aggressive behavior of human epithelial ovarian cancer. Cancer Res. 2005; 65:3025-3029.

7. Zhang M, Behbod F, Atkinson RL, Landis MD, Kittrell F, Edwards D, Medina D, Tsimelzon A, Hilsenbeck S, Green JE, Michalowska AM and Rosen JM. Identification of tumor-initiating cells in a p53-null mouse model of breast cancer. Cancer Res. 2008; 68:4674-4682.

8. Chau WK, Ip CK, Mak AS, Lai HC and Wong AS. c-Kit mediates chemoresistance and tumor-initiating capacity of ovarian cancer cells through activation of Wnt/beta-cateninATP-binding cassette G2 signaling. Oncogene. 2013; 32:2767-2781.

9. Ip CK and Wong AS. Exploiting p70 S6 kinase as a target for ovarian cancer. Expert Opin Ther Targets. 2012; 16:619-630

10. Pon YL, Zhou HY, Cheung AN, Ngan HY and Wong AS. p70 S6 kinase promotes epithelial to mesenchymal transition through snail induction in ovarian cancer cells. Cancer Research. 2008; 68:6524-6532.

11. Zhou HY and Wong AS. Activation of p70S6K induces expression of matrix metalloproteinase 9 associated with hepatocyte growth factor-mediated invasion in human ovarian cancer cells. Endocrinology. 2006; 147:2557-2566.

12. Ip CK, Cheung AN, Ngan HY and Wong AS. p70 S6 kinase in the control of actin cytoskeleton dynamics and directed migration of ovarian cancer cells. Oncogene. 2011; 30:2420-2432.

13. Esquela-Kerscher A and Slack FJ. Oncomirs - microRNAs with a role in cancer. Nat Rev Cancer. 2006; 6:259-269.
14. Chendrimada TP, Gregory RI, Kumaraswamy E, Norman J, Cooch N, Nishikura K and Shiekhattar R. TRBP recruits the Dicer complex to Ago 2 for microRNA processing and gene silencing. Nature. 2005; 436:740-744.

15. Lund E, Guttinger S, Calado A, Dahlberg JE and Kutay U. Nuclear export of microRNA precursors. Science. 2004; 303:95-98.

16. Niessen CM and Gottardi CJ. Molecular components of the adherens junction. Biochim Biophys Acta. 2008; 1778:562-571

17. Sundfeldt K. Cell-cell adhesion in the normal ovary and ovarian tumors of epithelial origin; an exception to the rule. Mol Cell Endocrinol. 2003; 202:89-96.

18. Derycke LD and Bracke ME. N-cadherin in the spotlight of cell-cell adhesion, differentiation, embryogenesis, invasion and signalling. Int J Dev Biol. 2004; 48:463-476.

19. Hosono S, Kajiyama H, Terauchi M, Shibata K, Ino K, Nawa A and Kikkawa F. Expression of Twist increases the risk for recurrence and for poor survival in epithelial ovarian carcinoma patients. Br J Cancer. 2007; 96:314-320.

20. Malki S, Bibeau F, Notarnicola C, Roques S, Berta P, Poulat $\mathrm{F}$ and Boizet-Bonhoure B. Expression and biological role of the prostaglandin D synthase/SOX9 pathway in human ovarian cancer cells. Cancer Lett. 2007; 255:182-193.

21. Bartel DP. MicroRNAs: target recognition and regulatory functions. Cell. 2009; 136:215-233.

22. Iorio MV, Visone R, Di Leva G, Donati V, Petrocca F, Casalini P, Taccioli C, Volinia S, Liu CG, Alder H, Calin GA, Menard S and Croce CM. MicroRNA signatures in human ovarian cancer. Cancer Res. 2007; 67:8699-8707.

23. Nam EJ, Yoon H, Kim SW, Kim H, Kim YT, Kim JH, Kim JW and Kim S. MicroRNA expression profiles in serous ovarian carcinoma. Clin Cancer Res. 2008; 14:2690-2695.

24. Zhang L, Volinia S, Bonome T, Calin GA, Greshock J, Yang N, Liu CG, Giannakakis A, Alexiou P, Hasegawa K, Johnstone CN, Megraw MS, Adams S, Lassus H, Huang J, Kaur S, et al. Genomic and epigenetic alterations deregulate microRNA expression in human epithelial ovarian cancer. Proc Natl Acad Sci U S A. 2008; 105:7004-7009.

25. Zhang L, Huang J, Yang N, Greshock J, Megraw MS, Giannakakis A, Liang S, Naylor TL, Barchetti A, Ward MR, Yao G, Medina A, O'Brien-Jenkins A, Katsaros D, Hatzigeorgiou A, Gimotty PA, et al. microRNAs exhibit high frequency genomic alterations in human cancer. Proc Natl Acad Sci U S A. 2006; 103:9136-9141.

26. Kurzynska-Kokorniak A, Koralewska N, Pokornowska M, Urbanowicz A, Tworak A, Mickiewicz A and Figlerowicz M. The many faces of Dicer: the complexity of the mechanisms regulating Dicer gene expression and enzyme activities. Nucleic Acids Res. 2015; 43:4365-4380.

27. Trabucchi M, Briata P, Garcia-Mayoral M, Haase AD, Filipowicz W, Ramos A, Gherzi R and Rosenfeld MG. The RNA-binding protein KSRP promotes the biogenesis of a subset of microRNAs. Nature. 2009; 459:1010-1014. 
28. Brennan SE, Kuwano Y, Alkharouf N, Blackshear PJ, Gorospe $\mathrm{M}$ and Wilson GM. The mRNA-destabilizing protein tristetraprolin is suppressed in many cancers, altering tumorigenic phenotypes and patient prognosis. Cancer Res. 2009; 69:5168-5176.

29. Plante I, Davidovic L, Ouellet DL, Gobeil LA, Tremblay S, Khandjian EW and Provost P. Dicer-derived microRNAs are utilized by the fragile $\mathrm{X}$ mental retardation protein for assembly on target RNAs. J Biomed Biotechnol. 2006; 2006:64347.

30. Briata P, Forcales SV, Ponassi M, Corte G, Chen CY, Karin M, Puri PL and Gherzi R. p38-dependent phosphorylation of the mRNA decay-promoting factor KSRP controls the stability of select myogenic transcripts. Mol Cell. 2005; 20:891-903.

31. Zhang X, Wan G, Berger FG, He X and Lu X. The ATM kinase induces microRNA biogenesis in the DNA damage response. Mol Cell. 2011; 41:371-383.

32. Carrick DM and Blackshear PJ. Comparative expression of tristetraprolin (TTP) family member transcripts in normal human tissues and cancer cell lines. Arch Biochem Biophys. 2007; 462:278-285.

33. Sanduja S, Kaza V and Dixon DA. The mRNA decay factor tristetraprolin (TTP) induces senescence in human papillomavirus-transformed cervical cancer cells by targeting E6-AP ubiquitin ligase. Aging (Albany NY). 2009; 1:803-817. doi: 10.18632/aging.100086.

34. Sohn BH, Park IY, Lee JJ, Yang SJ, Jang YJ, Park KC, Kim DJ, Lee DC, Sohn HA, Kim TW, Yoo HS, Choi JY, Bae YS and Yeom YI. Functional switching of TGF-beta 1 signaling in liver cancer via epigenetic modulation of a single CpG site in TTP promoter. Gastroenterol. 2010; 138:1898-U1880.

35. Garcia-Mayoral MF, Diaz-Moreno I, Hollingworth D and Ramos A. The sequence selectivity of KSRP explains its flexibility in the recognition of the RNA targets. Nucleic Acids Res. 2008; 36:5290-5296.

36. Tavazoie SF, Alarcon C, Oskarsson T, Padua D, Wang QQ, Bos PD, Gerald WL and Massague J. Endogenous human microRNAs that suppress breast cancer metastasis. Nature. 2008; 451:147-U143.

37. Kim TH, Song JY, Park H, Jeong JY, Kwon AY, Heo JH, Kang H, Kim G and An HJ. miR-145, targeting high-mobility group A2, is a powerful predictor of patient outcome in ovarian carcinoma. Cancer Lett. 2015; 356:937-945.

38. Cho WCS. MicroRNAs as therapeutic targets and their potential applications in cancer therapy. Expert Opin Ther Targets. 2012; 16:747-759.

39. Casalini P and Iorio MV. MicroRNAs and future therapeutic applications in cancer. J BUON. 2009; 14:S17-22.

40. Pramanik D, Campbell NR, Karikari C, Chivukula R, Kent OA, Mendell JT and Maitra A. Restitution of tumor suppressor microRNAs using a systemic nanovector inhibits pancreatic cancer growth in mice. Mol Cancer Ther. 2011; 10:1470-1480.

41. Perez-Tenorio G, Karlsson E, Waltersson MA, Olsson B, Holmlund B, Nordenskjold B, Fornander T, Skoog L and Stal O. Clinical potential of the mTOR targets S6K1 and S6K2 in breast cancer. Breast Cancer Res Treat. 2011; 128:713-723.

42. Filonenko VV, Tytarenko R, Azatjan SK, Savinska LO, Gaydar YA, Gout IT, Usenko VS and Lyzogubov VV. Immunohistochemical analysis of S6K1 and S6K2 localization in human breast tumors. Exp Oncol. 2004; 26:294-299.

43. Nozawa $H$, Watanabe $T$ and Nagawa H. Phosphorylation of ribosomal p70 S6 kinase and rapamycin sensitivity in human colorectal cancer. Cancer Lett. 2007; 251:105-113.

44. Sahin F, Kannangai R, Adegbola O, Wang J, Su G and Torbenson M. mTOR and P70 S6 kinase expression in primary liver neoplasms. Clinical Cancer Res. 2004; 10:8421-8425.

45. Hennessy BT, Smith DL, Ram PT, Lu Y and Mills GB. Exploiting the PI3K/AKT pathway for cancer drug discovery. Nat Rev Drug Discov. 2005; 4:988-1004.

46. Yuhas JM, Li AP, Martinez AO and Ladman AJ. Simplified Method for Production and Growth of Multicellular Tumor Spheroids. Cancer Res. 1977; 37:3639-3643.

47. Aktipis S and Panayotatos N. A kinetic study on the mechanism of inhibition of RNA synthesis catalyzed by DNA-dependent RNA polymerase. Differences in inhibition by ethidium bromide, 3,8-diamino-6-ethylphenanthridinium bromide and actinomycin d. Biochim Biophys Acta. 1981; 655:278-290. 